\title{
Synthesis, Spectroscopic Characterization and Theoretical Study of Schiff Bases Derived from Phenylsulfonylamide
}

\author{
J. S. Hadi ${ }^{\text {, B. K. Alsalami }}$, and A. H. Essa ${ }^{\text {b1 }}$ \\ ${ }^{a}$ Department of Chemistry, College of Education, University of Basrah, Basrah, Iraq \\ ${ }^{b}$ Department of Chemistry, College of Science, University of Basrah, Basrah, Iraq
}

Received 3 April 2009, accepted in revised form 20 June 2009

\begin{abstract}
The synthesis, characterization, and theoretical study of two Schiff bases of ligands derived from condensation of sulphoacetamide sodium with 4-methoxy benzaldehyde and salicalaldehyde arereported. Spectroscopic techniques, including IR, UV, ${ }^{1} \mathrm{H}$ NMR, and $\mathrm{CHN}$ analysis were used to identify the product. The calculated HOMO is largely localized on the $\mathrm{N}$-benzylideneaniline fragment, while the calculated LUMO of the studied molecule is seen to be substantially localized along the $\mathrm{C}-\mathrm{C}$ axis of the conjugated system.

Keyword: Sulphoacetamide sodium complex; Schiff bases; Sulpha drug; Semi-empirical (PM3) methods.
\end{abstract}

C을 2009 JSR Publications. ISSN: 2070-0237 (Print); 2070-0245 (Online). All rights reserved.

DOI: $10.3329 /$ jsr.v1i3.2589 J. Sci. Res. 1 (3), 563-568 (2009)

\section{Introduction}

Sulphonamide derivatives have been the subject of intensive studies, where a wide variety of those derivatives have been prepared and used in various physical, biological and pharmacological fields [1-4]. Schiff bases are among the most studied sulphonamide derivatives which have been used for numerous biological applications [5, 6]. These types of derivatives are very important because of their varied structures and biological activities [7-10].

Compounds containing the sulphonamide group have long been used for diseases like, malaria and convulsion [11]. The condensation products of sulphadrugs like sulphanilamide, sulphadiazine etc. with aldehydes, ketones or their derivative gives

\footnotetext{
${ }^{1}$ Corresponding author: alihashemalyunis@yahoo.com
} 
biologically active Schiff bases [12, 13], and their biological activity increase with complexation $[14,15]$.

The subject of this paper is to prepare a ligand system with available site $(\mathrm{N}-\mathrm{Na}, \mathrm{C}=\mathrm{N}$ and $\mathrm{OH}$ ), where these two compounds have been classified as bidentate (compound 1) and tridentate ligands (compound 2) (scheme 1).

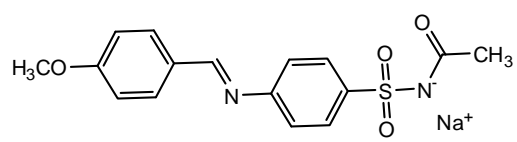

Compound 1

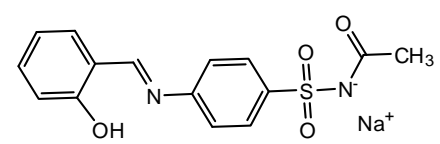

Compound 2

Scheme 1

\section{Experimental}

\subsection{Materials and physical measurements}

Sulphaacetamide sodium, 4-methoxybenzaldehyde and salicalaldehyde were purchased from (Fluka). All other solvents were of reagent grade and distilled prior to use. Melting point were determined on a BUCHI melting point 501, electronic spectra were recorded by PG T80+ instrument, IR spectra were measured on shimadzu spectrophotometer as $\mathrm{KBr}$ pellets in the region $4000-400 \mathrm{~cm}^{-1}$, elemental analyses were performed on Euro vector EA 3000A (Italy). The ${ }^{1} \mathrm{HNMR}$ spectra were recorded in DMSO $-\mathrm{d}^{6}$ on Bruker $500 \mathrm{MHz}$ spectrometer using TMS an internal standard. The synthesis of the two compounds is shown in scheme 2 .

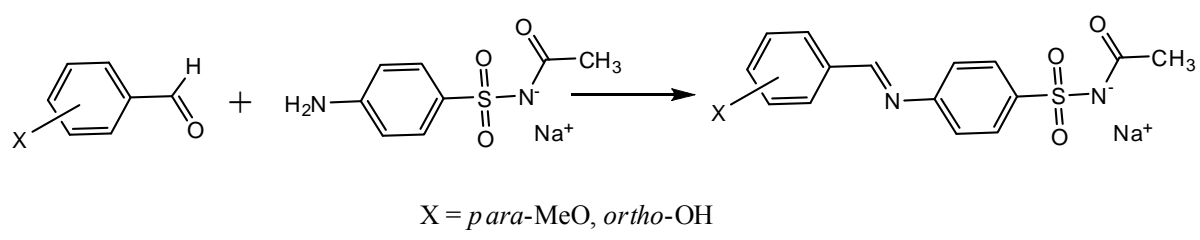

Scheme 2

\subsection{Synthesis of sodium (E)-acetyl(4-(4-methoxybenzylideneamino)phenylsulfonyl) amide (compound 1)}

$2.2 \mathrm{~g}(0.01 \mathrm{~mol})$ of sodium acetyl(4-aminophenylsulfonyl)amide and $1.36 \mathrm{~g}(0.01 \mathrm{~mol})$ of 4 methoxy benzaldehyde dissolved in $25 \mathrm{ml}$ methanol. The resulting solution was refluxed for $3 \mathrm{~h}$. The pale yellow precipitate which was formed in the reaction was filtered off, washed with cooled ethanol and dried : yield $84 \%$, m.p. $296-298^{\circ} \mathrm{C}$. The result of elemental analysis is as follows: found (calculated); C: 54.62 (54.23), H: 4.04 (4.23), N: 8.02 (7.90), S: 8.87 (9.03). 


\subsection{Synthesis of sodium (E)-acetyl(4-(2-hydroxybenzylideneamino)phenylsulfonyl) amide (Compound 2)}

$2.2 \mathrm{~g}(0.1 \mathrm{~mol})$ of sodium acetyl(4-aminophenylsulfonyl)amide and $2 \mathrm{ml}$ (excess) of salicyaaldehyde dissolved in $10 \mathrm{ml}$ methanol. The resulting solution was refluxed for $4 \mathrm{~h}$. The product was isolated as a yellow-orange powder on the evaporation of the solvent, and re-crystallized in $n$-hexane yield $81 \%$ as yellow crystal m.p. $274-275^{\circ} \mathrm{C}$. Elemental analysis: found (calculated); C: 52.11(52.94), H: 3.91(3.82), N: 8.43(8.23), S: 9.26(9.41).

\section{Results and Discussion}

The elemental analyses of compounds are in agreement with formula. The compounds are stable with high melting point $\left(>270^{\circ} \mathrm{C}\right)$. They are freely soluble in water, DMF and DMSO and sparingly soluble in less polar solvent hexane , and benzene.

Semi-empirical methods are done on HYPERCHEM program version 7.5 [16] running on a windows XP workstation with a Pentium IV PC. The HOMO and LUMO of sodium (E)-acetyl(4-(4-methoxybenzylideneamino)phenylsulfonyl) amide (compound 1) and sodium (E)-acetyl(4-(2-hydroxybenzylideneamino)phenylsulfonyl) amide (Compound 2), were done by performing semi-empirical methods. Semi-empirical self-consistent-field molecular orbital (SCF-MO) method at PM3 level [17] within the restricted Hartree-Fock (RHF) [18] formalism has been considered. Geometry optimization has been carried out by using a conjugate gradient method (Polak-Ribiere algorithm) [19]. The SCF convergency is set to $0.001 \mathrm{kcal} \mathrm{mol}^{-1}$ and the RMS gradient is set to $0.001 \mathrm{kcal} /(\AA \mathrm{mol})$ in the calculations.

\subsection{Electronic spectra}

The electronic spectra of compounds recorded in $\mathrm{H}_{2} \mathrm{O}$ solution, show absorption bands at $286 \mathrm{~nm}\left(\epsilon=10500 \mathrm{~mol} . \mathrm{Lit}^{-1} \cdot \mathrm{cm}^{-1}\right)$ (compound 1), and $324 \mathrm{~nm}\left(\epsilon=12170 \mathrm{~mol} \cdot \mathrm{lit}^{-1} \cdot \mathrm{cm}^{-1}\right)$ (compound 2 ) are assigned to imine $\pi-\pi^{*}[20]$. The absorption bands appearing at 263 $\mathrm{nm}$ (compound 1) and $269 \mathrm{~nm}$ (compound 2) may be tentatively attributed to $\pi-\pi^{*}$ of the ring.

\subsection{IR spectra}

The medium band at $3028-3045 \mathrm{~cm}^{-1}$ are assigned to the aromatic $\mathrm{C}-\mathrm{H}$ stretch, both compounds shows the aliphatic $v \mathrm{C}-\mathrm{H}\left(-\mathrm{CH}_{3}\right.$ groups) at $2990 \mathrm{~cm}^{-1}$ (asym.) and $2930 \mathrm{~cm}^{-1}$ (sym.) as a medium-weak bands. Compound 2 show a band at $3234 \mathrm{~cm}^{-1}$, attributed to $\mathrm{v}$ $(\mathrm{O}-\mathrm{H})$ stretch. Both the compounds show a strong $v \mathrm{C}=\mathrm{O}$ bands in the $1680 \mathrm{~cm}^{-1}$ (compound 1) and $1691 \mathrm{~cm}^{-1}$ (compound 2). The $v(\mathrm{C}=\mathrm{N}$ ) bands appear as a strong bands at $1630 \mathrm{~cm}^{-1}$ (compound 1) and $1614 \mathrm{~cm}^{-1}$ (compound 2), also both compounds show a very strong bands at $1321-1325 \mathrm{~cm}^{-1}$ and $1140-1151 \mathrm{~cm}^{-1}$, attributed to $v$ asym. $\mathrm{SO}_{2}$ and $v$ sym. $\mathrm{SO}_{2}$, respectively [21]. 


\section{3. ${ }^{1} \mathrm{HNMR}$}

The ${ }^{1}$ HNMR spectra data of compounds are given in Table 1 . In the ${ }^{1} \mathrm{HNMR}$ spectra of compounds 1 the $\mathrm{OCH}_{3}$ protons appears as singlet at $3.84 \mathrm{ppm}$. The O-H proton in compound 2 appears as a broad signal at $12.9 \mathrm{ppm}$. Methyl protons in both the compounds appears as a singlet signal at $1.66 \mathrm{ppm}$ (Fig. 1), other aromatic proton of the compounds were observed at 7.07-7.9 ppm (comp. 1) and at 6.97-7.8 ppm (comp. 2). The azomethine proton appears as a singlet signal at $8.53 \mathrm{ppm}$ (comp.1) and as a doublet at 9.0ppm $(\mathrm{J}=10.55 \mathrm{~Hz})[22]$, suggesting that the azomethine proton involved in the hydrogen bonded with $\mathrm{OH}$ group [23].

Table 1. UV-Visible, IR, and ${ }^{1} \mathrm{NMR}$ spectral data of compounds.

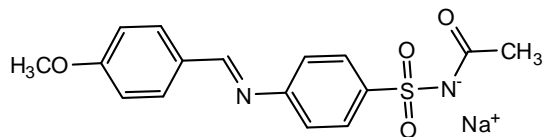

Compound 1

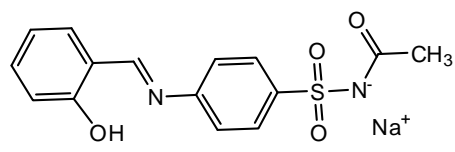

Compound 2

\begin{tabular}{|c|c|c|c|}
\hline $\begin{array}{l}\text { Comp. } \\
\text { No. }\end{array}$ & $\begin{array}{l}\text { UV-Visible in } \mathrm{H}_{2} \mathrm{O} \lambda \\
\mathrm{nm}\left(\mathrm{C} \text { mol.lit }{ }^{-1} \cdot \mathrm{cm}^{-1}\right)\end{array}$ & IR peaks $\left(\mathrm{cm}^{-1}\right)$ & $\begin{array}{l}{ }^{1} \mathrm{NMR} \text { chem. Shift } \\
\delta(\mathrm{ppm})\end{array}$ \\
\hline 1 & $\begin{array}{l}286 \mathrm{~nm}(€=10500) \\
263 \mathrm{~nm}(€=7400)\end{array}$ & 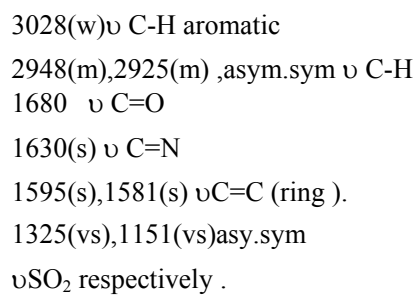 & $\begin{array}{l}1.66\left(\mathrm{~s}, 3 \mathrm{H}, \mathrm{CH}_{3}\right) \\
7.07-7.9((\mathrm{~m}, 8 \mathrm{H} \\
\text {,aromatic) } \\
8.53(\mathrm{~s}, 1 \mathrm{H}, \mathrm{HC}=\mathrm{N}\end{array}$ \\
\hline 2 & $\begin{array}{l}324 \mathrm{~nm}(\mathrm{C}=12170) \\
269 \mathrm{~nm}(\mathrm{C}=6800)\end{array}$ & $\begin{array}{l}3234 \text { (br.) vO-H } \\
3045(\text { w) } \cup \text { C-H aromatic } \\
2946(\mathrm{~m}), 2905(\mathrm{~m}) \text {, asym.sym } \cup \mathrm{C}-\mathrm{H} \\
1691(\mathrm{~s}) \cup \mathrm{C}=\mathrm{O} \\
1614(\mathrm{~s}) \cup \mathrm{C}=\mathrm{N} \\
1591(\mathrm{~s}) \cup \mathrm{C}=\mathrm{C} \text { ring. } \\
1321(\mathrm{vs}), 1140 \text { (vs)asy.sym } \\
\mathrm{USO}_{2} .\end{array}$ & $\begin{array}{l}1.66\left(\mathrm{~s}, 3 \mathrm{H}, \mathrm{CH}_{3}\right) \\
6.97-7.8((\mathrm{~m}, 8 \mathrm{H} \\
\text {,aromatic }) \\
9.0(\mathrm{~s}, 1 \mathrm{H}, \mathrm{HC}=\mathrm{N}) \\
12.9(\mathrm{br} .1 \mathrm{H}, \mathrm{OH})\end{array}$ \\
\hline
\end{tabular}

The balls and cylinders and some of selected structural parameters (bond length and angles) of the optimized geometries are shown in Fig. 1. 


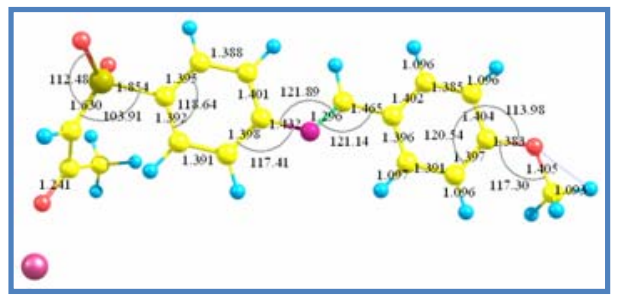

Compound 1

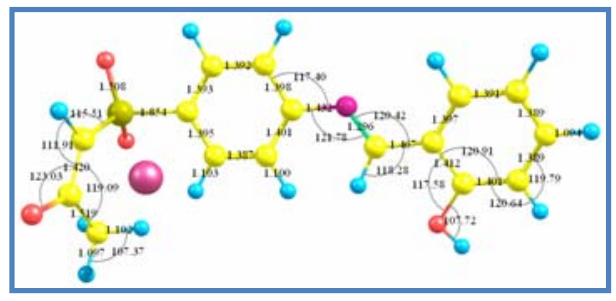

Compound 2

Fig. 1. The balls and cylinders and some of structural parameters, bond length $(\AA)$ and angles $\left(^{\circ}\right)$ of the studied molecules.

As shown in this figure, there is no obvious trend for the variation of these parameters. The values of the bond length and angles of the optimized geometries are quite similar to the experimental results of the corresponding compounds [22, 23].

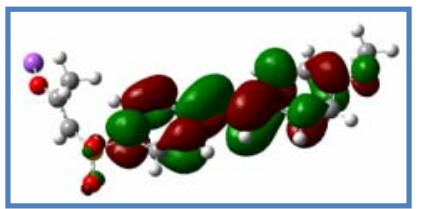

LUMO

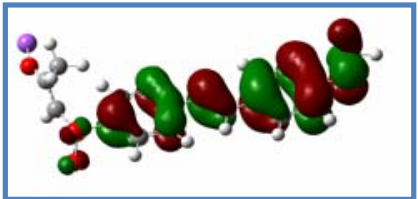

HOMO

Compound 1

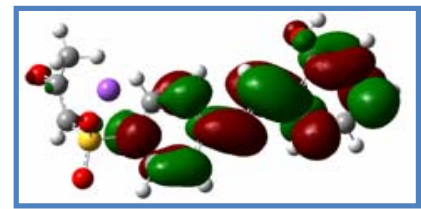

LUMO

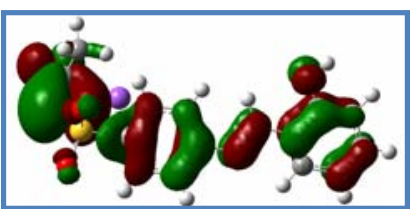

HOMO

Compound 2

Fig. 2. The calculated 3D HOMO and LUMO of the studied molecules.

The calculated frontier bonding molecular orbitals (MO) are shown in Fig. 2. The calculated HOMO is largely localized on the $N$-benzylideneaniline fragment. The electronic character is also of interest with respect to its reactivity, especially towards nucleophilic agents. The calculated LUMO (electron acceptor orbital) of the studied molecule is seen to be substantially localized along the $\mathrm{C}-\mathrm{C}$ axis of the conjugated system.

\section{References}

1. M. Verma, S. N. Pandeya, K. N. Singh, and J. P. Stables, Acta Pharm. 54, 49 (2004).

2. J. O. McNamara, Drugs Effective in the Therapy of the Epilepsies, in The Pharmacological Basis of Therapeutics, Eds. J. G. Hardman et al. 9th ed., (McGraw Hill, New York, 1990) pp. 461-486. 
3. A. Sabers and L. Gram, Drugs 60, 23 (2000). doi:10.2165/00003495-200060010-00003

4. J. W. Britton and E. L. So, J. Epilepsy 8, 267 (1995). doi:10.1016/0896-6974(95)00049-6

5. W. Loscher, Eur. J. Pharmacol. 342, 1 (1998). doi:10.1016/S0014-2999(97)01514-8

6. J. R. Dimmock and G. B. Baker, Epilepsia 35, 648 (1994). doi:10.1111/j.1528-1157.1994.tb02486.x

7. S. N. Pandeya, P. Yogeeswari and J. P. Stables, Eur. J. Med. Chem. 35, 879 (2000). doi:10.1016/S0223-5234(00)01169-7

8. S. N. Pandeya, B. Mishra, P. N. Singh and D. C. Rupainwar, Pharmacol. Res. 37, 17 (1998). doi:10.1006/phrs.1997.0250

9. S. N. Pandeya, H. Manjula and J. P. Stables, Pharmazie 56, 121 (2001).

10. S. N. Pandeya, V. Mishra, I. Ponnilavarasan and J. P. Stables, Pol. J. Pharmacol, 52, 283 (2000).

11. A. Varshny and J. P. Tandon, Proc. Indian Acod. SCI. 97, 141 (1986).

12. M. Jain, S. Nehra, P. C. Trivedi, and R.V. Singh, Metal-Based Drugs 9, 53 (2002). doi:10.1155/MBD.2002.53

13. J. S. Hadi and B.K. Alsalami, National Journal of Chem. 29, 184 (2008).

14. M. K. Gupta, H. L. Singh, S. Varshny and A.K. Varshney, Bioinorg. Chem. Appl., 1, 309 (2003). doi:10.1155/S1565363303000244

15. M. Jain, and R.V. Singh, Bioinorg. Chem. Appl. 6, 1 (2006).

16. HYPERCHEM ${ }^{\mathrm{TM}}$ release 7.52. Windows Molecular Modeling System, Hypercube, Inc. and Autodesk, Inc. Developed by Hypercube, Inc.

17. M. J. S. Dewar, E.G. Zoebisch, E.F. Healy, and J. J. P. Stewart, J. Am. Chem. Soc. 107, 3902 (1985). doi:10.1021/ja00299a024

18. C. C. J. Roothaan, Rev. Mod. Phys. 23, 69 (1951). doi:10.1103/RevModPhys.23.69

19. P. Fletcher, Practical Methods of Optimization (Wiley, New York, 1990).

20. D. M. Boghaei and M. Gharagozlou, Spect. Acta, Part A, 67, 944 (2007).

21. G. Sogrates, Infrared Characteristic group frequencies (Willey Inter-science Publication, 1980)

22. S. Baluja, A. Solanki, and N. Kachhadia, J. Iran. Chem. Soc. 3, 312 (2006).

23. H. Univer, E. Kendi, K. Guven, and T. Nuridurlu, Z. Naturforch 57b, 685 (2002). 